\title{
A arquitetura política de construção do terroir do café no cerrado de Minas Gerais
}

\section{Marcelo Orozco Morais}

\section{Introdução}

Ao longo da história econômica do Brasil, o café contou com um forte apoio governamental, quer no apoio à produção, quer na comercialização, com, por exemplo, a compra de excedentes e políticas de preços mínimos - que na maior parte das vezes funcionava como preço máximo. Tal prática criou uma forte dependência dos produtores em relação ao Estado, cuja atuação criou, na realidade, um grande mercado nacional de produção do café orientado pelo preço médio ${ }^{1}$.

Dentre os instrumentos reguladores, o que teve maior interferência na política cafeeira foi o Instituto Brasileiro do Café (IBC), criado em 1952 e extinto em 1990, no Governo de Fernando Collor de Mello. Segundo Farina (1997), a garantia de preços do IBC foi prejudicial ao sistema agroindustrial do café no país. Isso porque esta política não estimulava a busca pela qualidade e

IIIIIIIIIIIIIIIIIIIIIIIIIIIIIIIIIII

1 Até este período a classificação oficial do café se baseava em dois grupos. O grupo I contemplava os cafés de melhor qualidade, sem gosto de Rio Zona, enquanto o grupo II admitia cafés com gosto de Rio Zona. Esta classificação era insuficiente para abarcar todos os tipos de cafés produzidos no país, sobretudo no grupo I onde há uma grande variedade de cafés especiais. Cabe observar que o termo Rio Zona se refere ao café outrora produzido no Rio de Janeiro, classificado como um café de gosto ruim e por isso de baixa remuneração no mercado. (FARINA, 1997). sim pela quantidade produzida. Esse fato levou os produtores a não investir em melhorias da lavoura, uma vez que o investimento não seria recompensado na hora da venda do produto, visto que toda produção seria vendida em grande lote. Até então não havia no Brasil um processo de certificação de origem do produto e do produtor, fato que provocava oscilações de qualidade.

Essa política deteriorou a imagem do "Café do Brasil", chancela de venda do produto, no mercado externo, transformando-o num produto de segunda linha, o qual não figurava como o principal elemento na formação do blend ${ }^{2}$ dos grandes consumidores de café no mercado mundial, mas sim como um complemento, o que significava menor remuneração pelo produto ${ }^{3}$.

É importante considerar que o grau de exigência, em termos de qualidade, em mercados como Europa e Estados Unidos é mais elevado do que em nosso mercado interno. Isso significa que aqui se suporta oscilações de qualidade que não

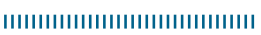

2 O blend é a mistura formada por diversos tipos de cafés, como robusta e arábica,de várias procedências. Cada empresa possui seu próprio blend, que caracteriza seu posicionamento no mercado em função de preço e classificação. O blend de cada empresa é considerado como segredo industrial.

3 O café brasileiro representa o maior volume físico na composição do blend dos cafés internacionais devido a seu maior corpo, mas não é o elemento determinante de sabor do produto.

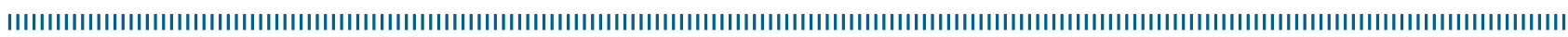
Como citar este artigo:

MORAIS, Marcelo Orozco. "A arquitetura política de construção do terroir do Café no Cerrado de Minas Gerais”. In: RÜCKERT, A. A.; SILVA, A. C. P. da; SILVA, G. de V. (Orgs.). Geografia Política, Geopolítica e Gestão do Território: integração sul-americana e regiões periféricas. Porto Alegre: Editora Letra1, 2018, p. 329-340 
são admitidas em outros mercados mais exigentes. O brasileiro como consumidor de café possui a percepção de que o melhor café produzido no país é direcionado ao mercado externo, ficando o mercado interno com o refugo desse produto. A sabedoria popular ainda aponta que, muitas vezes, o que é consumido é uma mistura de café com outros elementos, tais como: casca de milho, feijão, palhas e outros ${ }^{4}$.

A década de 1990 marcou a entrada do Brasil em uma nova orientação política e econômico. Após um longo período de recessão econômica e inflação elevada o país insere-se no contexto do que genericamente é denominado como neoliberalismo, cuja adoção vai trazer uma série de mudanças para a economia do país e o setor cafeeiro não ficaria imune ao novo cenário.

Foi nesta transição, ocorrida no início da década de 1990, que se deu o grande salto da região de Patrocínio. Convém lembrar que há cerca de duas décadas já se produzia café na região, mas em nada esta se diferenciava das outras, a não ser pelo fato de que já se sabia que ali se obtinha um café de boa qualidade, segundo análises superficiais. Mas isso não significava melhor preço para o produtor, já que o preço do café era tirado por uma média de mercado sem se levar em conta diferenças de qualidade e de origem. Criou-se um círculo vicioso, em que o produtor não investia em melhorias na produção porque o mercado não remunerava e o mercado não remunerava sob o argumento de que o produtor não investia em melhorias para elevar a qualidade.

A extinção do IBC deixou a cafeicultura brasileira numa situação delicada. O término da garantia de preços revelou uma estrutura produtiva que não

\footnotetext{
|||||||||||||||||||||||||||||||||||||

4 Segundo João Segges, classificador de café aposentado do extinto IBC, em entrevista ao autor em 2016 essa visão é equivocada. O que se bebe no país é café, muitas vezes puro. O que ocorre é que o ponto de torra tem que ser elevado para mascarar uma série de grãos defeituosos que não passariam por um processo de classificação para a venda no mercado externo. De um modo geral, grande parte do café consumido no mercado interno é classificada como rio zona ou riado, ou seja, o ponto mais baixo de classificação do produto. O baixo poder aquisitivo da maior parte da população torna os cafés superiores ou especiais, de melhor qualidade, proibitivos para a mesma.
}

oferecia resposta à demanda do mercado mundial por um aumento de qualidade, levando um grande número de produtores a erradicar seus pés de café ou até mesmo à falência.

Com o fracasso das negociações para a criação de um novo órgão governamental de regulação de preços, os plantadores, exportadores e torrefadores tiveram que tomar iniciativas próprias para solucionar o problema da queda de qualidade e preço do produto.

Neste ambiente de mudanças no setor, passa a ganhar peso o papel das cooperativas, associações de produtores e empresas de exportação. A iniciativa privada teve que reestruturar uma atividade produtiva que na maior parte do tempo esteve, historicamente, regulada pelo Estado, buscando soluções para o aumento de competitividade e elevação da qualidade, o que permitiria não só a abertura de novos mercados, como também a manutenção de clientes tradicionais.

\section{A criação do terroir do Café do Cerrado}

A queda de qualidade do café brasileiro foi tão acentuada que as próprias empresas internacionais compradoras do produto tomaram a iniciativa de buscar soluções para a elevação da qualidade do produto. O café brasileiro é fundamental para a composição do blend vendido no mercado internacional. No caso do café da marca italiana Illy, $70 \%$ da sua composição é feita de café brasileiro, não sendo possível obter um substituto no mercado externo que consiga entregar o mesmo volume com as características do café brasileiro ${ }^{5}$.

Dentre as iniciativas, merece destaque a ILLY Café, terceira maior torrefadora de café para expresso do mundo, como aponta Zylbersztajn

IIIIIIIIIIIIIIIIIIIIIIIIIIIIIIIIIIII

50 café produzido no Brasil é, em sua grande maioria, beneficiado através da secagem em terreiro, diferente do café colombiano que é beneficiado através de via úmida, processo que reduz o corpo do café, comprometendo a qualidade da bebida. (FARINA, 1997). Neste aspecto, o café do cerrado tem no clima um forte aliado, pois conta com duas estações bem definidas, sendo que a seca coincide com o período da colheita e do beneficiamento, permitindo largamente o uso do terreiro para a secagem do café, reduzindo ainda a possibilidade de contaminação dos grãos por fungos e outros agentes afeitos à umidade. 
(1997). Esta empresa, em 1991, instituiu um concurso de qualidade do café em que poderiam se inscrever produtores de todo o Brasil. Os primeiros colocados receberiam um prêmio em dinheiro, além do comprometimento da empresa de comprar uma determinada cota de sua produção, por um preço acima da média paga pelo mercado.

Nas primeiras edições do concurso, a maioria dos produtores premiados era oriunda da região do Cerrado de Minas Gerais. Isso serviu de estímulo para os produtores se articularem e buscarem estratégias de aumento de qualidade, uma vez que a repercussão em termos de marketing para o produto era a melhor possível.

A avaliação do café em aspectos ligados, principalmente, à qualidade do produto não só no aspecto do grão, mas também na degustação, criou a percepção, um tanto óbvia, de que o café não era igual em todo o país. Um conjunto de fatores influi no resultado final, tais como: a espécie da planta, os tratos a ela dispensados, o clima e solo das regiões de plantio. Estes dois últimos constituíram-se no maior trunfo da região do Cerrado na obtenção de um produto com características únicas, que veio estimular um grupo de plantadores a investir em uma forma inovadora de gestão produtiva.

As reformas econômicas ocorridas no Brasil na década de 1990 abriram novas possibilidades para os produtores de café, que, ao mesmo tempo em que perdiam o "guarda-chuva protetor" do extinto IBC, vislumbravam a possibilidade de preencher lacunas de mercado com um café de melhor qualidade e melhor preço pago ao produtor, estimulando o investimento em melhorias em toda a cadeia produtiva do café, envolvendo desde o produtor rural, passando pela logística de embarque e comercialização e até mesmo ao marketing do produto. Nesse período da economia nacional consolidava-se a visão de que o setor privado era mais eficiente que o estatal para modernizar o país e a agricultura estava inserida no novo contexto, como afirma Mattei:

É preciso qualificar melhor as "reformas institucionais" da década de 1990 visando entender corretamente seu sentido, bem como seus impactos sobre o setor agropecuário brasileiro. Registra-se que na referida década esteve em voga a chamada política do "Novo Mundo Rural", a qual contemplava as estratégias definidas pelo Banco Mundial, especialmente para a América Latina. Tal estratégia embrenhada pelos princípios do "Consenso de Washington" definia claramente a desregulamentação das atividades econômicas agrícolas e determinava novas formas de regulação institucional que dessem maior poder aos agentes privados para que os mercados fossem capazes de reorganizar os setores produtivos e determinar o ritmo do crescimento econômico setorial. (MATTEI, 2015, p. 119).

Nesse contexto emerge em 1992, no município de Patrocínio (MG), o Conselho das Cooperativas do Cerrado o (CACCER), cujo grande objetivo é a elevação da qualidade do café produzido, obtendo maior remuneração pelo produto a partir de estratégias inéditas no setor. Esse conselho agrupou um conjunto de nove cooperativas de produtores da região, estabelecendo um conjunto de metas qualitativas, assim como fornecendo apoio técnico e de marketing. Iniciativa, portanto, tomada pelos próprios produtores e suas representações, sem interferência do Estado. Entretanto, é preciso ressaltar que o êxito do projeto só foi possível graças a um conjunto de políticas públicas elaboradas e instituídas nas instâncias federal, estadual e municipal, sem o qual não seria possível tamanho sucesso como veremos mais adiante.

Um dado fundamental neste processo de reestruturação produtiva engendrada no Cerrado mineiro, tendo o município de Patrocínio como pivô central, foi á criação de uma associação de produtores englobando uma série de associações e cooperativas de vários municípios produtores de café da região, quando o caminho natural seria a constituição de uma grande cooperativa aos moldes, por exemplo, da Cooxupé (Cooperativa de Guaxupé), maior cooperativa de café do mundo ${ }^{6}$. Saes (1997) nos oferece uma explicação:

A solução mais tradicional para atingir esses objetivos seria a constituição de uma cooperativa. Entretanto, essa forma de organização era vista com restrições. A

IIIIIIIIIIIIIIIIIIIIIIIIIIIIIIIIIII

6 Segundo o último senso agropecuário do IBGE disponível (2006). 
maneira de atuar das cooperativas costuma apresentar uma série de restrições ou vícios, e as principais restrições recaíam sobre os seguintes aspectos: pesada estrutura burocrática, formas usualmente limitadas de interação com os produtores, estrutura de representação igualitária, que muitas vezes inibe a criatividade individual. (SAES, 1997, p.7).

A pesada estrutura burocrática, muitas vezes, retardava a tomada de importantes decisões e criava um distanciamento de interesses entre os dirigentes e os cooperados, frequentemente limitando-se às operações de compra e venda do café, quando em muitas situações o produtor também precisa de assistência técnica, acesso ao crédito ou simplesmente uma orientação sobre um determinado problema, já que neste setor, como em outros da agropecuária brasileira, há um grande número de produtores com pouca instrução formal ${ }^{7}$. O CACCER e suas associações, montado sob uma estrutura de 'guarda-chuva', visava exatamente contornar esses problemas, partindo do pressuposto de que teria uma estrutura administrativa mais enxuta, mais ágil.

A concepção inicial do CACCER era para funcionar como uma estrutura empresarial, fugindo do associativismo ligado às cooperativas. Posteriormente reconheceu-se que o problema não era a cooperativa em si, mas a forma como ela era administrada. Isso fica claro nas palavras de Aguinaldo José de Lima ${ }^{8}$, idealizador do conselho de associações:

Não tinha nada de cooperativa, tanto é que a gente tinha bronca de cooperativa, a gente até brincava, que o símbolo do cooperativismo eram aqueles pinheirinhos, a gente era doido para arrumar uma motosserra e cortar

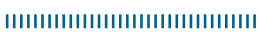

7 Em entrevista ao autor, em 26/07/2005, Aguinaldo José de Lima, considerado o criador do Caccer, argumentava que um dos grandes problemas dos produtores era expor seus problemas, suas dificuldades. Mesmo quando havia linhas de crédito disponíveis, o produtor não conseguia acesso por não saber redigir um projeto rudimentar que justificasse a tomada do crédito. Esta, em sua visão, é um papel primordial da associação. Sob sua ótica de produtor, muitas vezes o agricultor só precisa que alguém lhe escute, se solidarize com ele, para que não esmoreça e tome novas iniciativas inteligentes que trarão retorno. Para isso precisa de apoio, como o que é oferecido pela associação.

8 Em entrevista ao autor em 26/07/2006. aqueles pinheirinhos, porque a experiência que a gente tinha era cooperativa que vinha de fora pra cá, então, não era boa. Então, a gente tinha bronca de cooperativa, depois a gente viu que não era a cooperativa o problema e sim a forma como eles administravam. (LIMA, em entrevista ao autor, 2006).

Se livrar do modelo administrativo do sistema de cooperativa era então um imperativo para o que viria mais tarde a ser o selo Café do Cerrado, que hoje se constitui em um terroir ${ }^{9}$ de reconhecimento internacional.

É importante observar que a produção de café no cerrado mineiro difere de outras regiões tradicionais, como o sul e a zona da mata de Minas Gerais. As duas últimas possuem uma larga tradição na produção do café, enquanto a produção no Cerrado é mais recente e, sobretudo, nesta última predominam as médias e grandes propriedades, enquanto nas outras há um expressivo número de pequenos produtores familiares ${ }^{\mathbf{1 0}}$. Essas características talvez tenham facilitado a organização dos produtores do Cerrado em um modelo produtivo diferente das tradicionais cooperativas.

Em outro turno, Silva (2002) argumenta que as cooperativas são instrumentos importantes para a concretização de um modelo socioeconômico menos injusto, sobretudo em um país marcado por grandes contrastes internos como o Brasil. Para que tal intento seja atingido, as cooperativas devem mudar e retomar seus pressupostos. Em suas palavras:

A temática torna-se ainda mais importante por serem as cooperativas instituições de interface entre os mercados urbano e rural. Porém arcaicas em seus objetivos e nas formas de atingi-los, ou inibidas em sua organização por estatutos heterônomos, as cooperativas tornamse desacreditadas, ineficientes e autoritárias perante a sociedade atual. (SILVA, 2002, p. 33).

|||||||||||||||||||||||||||||||||||||

9 Terroir designa "uma extensão limitada de terra considerada do ponto de vista de suas aptidões agrícolas". (Tonietto. 2007 p.1) 10 Conforme o último censo agropecuário do IBGE disponível, publicado e realizado em 2006. 
Como proposta para tal retomada, o autor apresenta a teoria de Münster ${ }^{11}$ como uma possibilidade de substituição do modelo tradicional de cooperativas então vigente. Na nova proposta, a transformação consciente dos indivíduos viria através da política, do cooperativismo consciente, o que provocaria transformações individuais que beneficiariam a coletividade.

A proposta de Silva (2002), de que as cooperativas podem funcionar como um elemento fomentado para o crescimento de uma determinada região acabou por se confirmar com um próprio desdobramento do CACCER quando este resolveu criar sua própria cooperativa, denominada Expocaccer (Cooperativa Exportadora do Café do Cerrado) para comercializar diretamente o próprio café, livrando-se da, ou ao menos atenuando, dependência de intermediários, corretores e outros agentes ligados à comercialização do produto. Chamamos atenção para o fato de que a associação em um segundo momento criou sua própria cooperativa central, havendo boas razões para isso, conforme observa Saes:

À medida que as ações de apoio ao agronegócio dos associados foram se expandindo, o CACCER se viu obrigado, também, a partir para novas formas de organização. Em algumas das atividades, identificouse a que seria mais conveniente atuar como cooperativa, não como associação de classe. Isto surgiu em especial quando o CACCER passou a se envolver mais diretamente na comercialização do café dos associados, operacionalizando vendas futura e exportações de café. Nestas operações, as cooperativas levam vantagem sobre as associações, pois sobre elas incidem menos tributação e há maior facilidade para obtenção de crédito a juros mais baixo. (SAES, 1997, p. 10).

O CACCER tornou-se uma organização pioneira na elaboração de políticas de produção e comercialização e buscava fomentar uma estrutura produtiva que incentivasse os produtores regionais a investir no trato da lavoura e na incorporação de novas técnicas de produção, obtendo um produto de qualidade e mantendo a regularidade do mesmo, o que significaria melhor remuneração pelo produto do que a obtida até então.

|| ||||||||||||||||||||||||||||||||||||||

11 Para maior aprofundamento no tema, consultar Silva (2002).
Sediado na Associação dos cafeicultores de Patrocínio (ACARPA), o conselho iniciou uma série de articulações com outras cooperativas e associações da região para a elaboração de uma série de medidas que resultassem na obtenção de um café de melhor qualidade e, principalmente, que este café obtivesse reconhecimento no mercado interno e externo, diferenciando-se do que até então era produzido no país. Uma das primeiras medidas foi uma maior aproximação com a Empresa de Pesquisa Agropecuária de Minas Gerais (EPAMIG), que instalou uma fazenda experimental de café em Patrocínio, de modo que os conhecimentos elaborados e obtidos na mesma fossem difundidos por toda a região. Este ato é um marco inicial da relação do CACCER com o poder público, em que um conjunto de políticas públicas, elaboradas e aplicadas em múltiplas instâncias, foi fundamental para o êxito do projeto almejado pelo conselho e pelos produtores nele envolvidos.

O primeiro passo para buscar a diferenciação do café obtido foi o processo de certificação do produto produzido no Cerrado. Havia a preocupação por parte das organizações e cooperativas envolvidas no conselho que houvesse um mau uso da denominação café do cerrado, o que poderia comprometer a imagem do produto no mercado.

Seguindo esta lógica, uma das primeiras ações empreendidas foi o registro da marca Café do Cerrado, lançada em julho de 1993 e desde então administrada pelo CACCER.

O objetivo era garantir diferencial de preço para o produtor, evitando que o café fino do Cerrado servisse apenas para valorizar as ligas dos exportadores. Com este objetivo alcançado, o primeiro lote de café com a marca Café do Cerrado, totalizando 1400 sacas, foi exportado para a Bélgica, com prêmio de cerca de $8 \%$ sobre o preço que era praticado na época para o café da região. (SAES, 1997).

Segundo Saes (1997), apesar do Registro a marca Café do Cerrado ter sido um passo importante, não foi suficiente, uma vez que surgiu receio de que oportunistas utilizassem marca sem autorização do CACCER. Diante disso, pensou-se 
numa forma de certificação do café produzido no Cerrado. ${ }^{12}$.

A certificação de origem, prática comum nos mercados de alimentos e bebidas europeus, e mais recentemente no Chile e na Argentina, se aplica a produtos que possuem atributos qualitativos indissociáveis das características próprias de uma região ou microrregião bem delimitada, sejam elas relativas ao clima, ao solo, à história, a características culturais e à mão de obra. São produtos cujos processos de produção não são reproduzíveis fora do local de procedência tradicional. Em vista disso, são protegidos por uma legislação de produção e denominação de origem, que os certifica e fiscaliza sua autenticidade (SAES, 1997).

Em junho de 1993, o CACCER avança no sentido da certificação com a assinatura de um protocolo que envolveu o Instituto Mineiro de Agropecuária (IMA), a EPAMIG, a Empresa de Assistência Técnica e Extensão Rural do Estado de Minas Gerais (EMATER-MG), a Universidade Federal de Uberlândia e o próprio CACCER. Tal irrompeu em uma série de ações conjuntas que resultaram na na publicação da Portaria 165/95 do decreto 33.859 do governo mineiro que delimita regiões produtoras de café do Estado de Minas Gerais: Sul de Minas, Jequitinhonha, Montanhas de Minas e Cerrado. (Figura 1). (SAES,1997, p.10).

Finalmente em dezembro de 1996, foi instituído o Certicafé, certificado de origem para os cafés das quatro regiões delimitadas que seria emitido e controlado pelo Instituto Mineiro de Agropecuária (IMA). Desse período em diante, “os cafés produzidos no Cerrado Mineiro e submetidos ao IMA para exame de amostra devem portar na sacaria um selo contendo informações sobre a procedência do produto, entre outras." (SAES, 1997, p. 10).

Entendia-se que tal selo constituiria a garantia para o comprador a procedência do café que ele

||I||||||||||||||||||||||||||||||||||

12 A marca Café do Cerrado foi registrada indevidamente na Espanha por uma empresa exportadora, o que criou sérios problemas para o CACCER, via sua exportadora EXPOCACCER, vender seu café certificado na Europa. A Recuperação da marca só aconteceu em 2009 após negociação e indenização à empresa espanhola. Disponível em: <https://www.cafepoint.com.br/ noticias/mercado/caccer-recupera-marca-cafe-do-cerrado-57264n. aspx>. Acesso em: 26/02/2017. estava adquirindo. Seria uma forma de evitar que grupos de corretores, exportares e outros comerciantes de café tentassem vender outros tipos de café, de menor qualidade, alegando ser do Cerrado. Um ponto importante a ressaltar é que esta preocupação dos produtores está ligada à imagem da região, pois se o café vendido com procedência irregular não passar em uma prova de classificação, seu preço cai e produtor e vendedor recebem menos. Além disso, outro problema seria aquele relativo aos comentários sobre a expectativa frustrada acerca da qualidade do café do Cerrado comprado, o que certamente funcionaria como um marketing negativo para e região.

Com o lançamento do Certicafé, estava instituído no Brasil o primeiro produto agrícola com certificado de origem por região. Estruturouse na região do Cerrado Mineiro o conceito francês de terroir, que seria a origem geográfica, com características únicas para a obtenção de um determinado produto. (BROGGIO, 1999). Dessa forma, tem de se deixar claro o seguinte: a região delimitada do Cerrado Mineiro não é a única região de Cerrado do país a produzir café; ele também é produzido em Goiás e oeste da Bahia. Entretanto, o único café produzido em cerrado que pode fazer uso da marca Café do Cerrado, com seu atestado de qualidade reconhecida, é o produzido dentro da região demarcada do Cerrado Mineiro ${ }^{13}$. A região é composta de 55 municípios, totalizando uma área de $112.289,56 \mathrm{~km}^{2}$ e agrupando, aproximadamente, 4.500 produtores (Figura 2).

O lançamento do Certicafé foi uma grande vitória para o CACCER, mas os objetivos ainda estavam longe de ser alcançados. Isso porque o IMA não tinha um grande poder de fiscalização, além do que sua história está muito mais ligada à pecuária. Dessa forma, mesmo a marca Café do Cerrado pertencendo ao CACCER, muitos

||I||||||||||||||||||||||||||||||||||||

13 A Região dos Cerrados de Minas compreende as áreas geográficas delimitadas pelos paralelos $16^{\circ} 37^{\prime}$ a $20^{\circ} 13^{\prime}$ de latitude e $45^{\circ}$ $20^{\prime}$ a $49^{\circ} 48^{\prime}$ de longitude, abrangendo as regiões do Triângulo Mineiro, Alto Paranaíba e parte do Alto São Francisco e do Noroeste. Caracteriza-se por áreas de altiplano, com altitude de 820 a $1100 \mathrm{~m}$, com clima ameno, sujeitas à geada de baixa intensidade e com possibilidade de produção de bebida fina, de corpo mais acentuado. (Saes, 1997, p.5) 
Figura 1. A estrutura do CACCER.

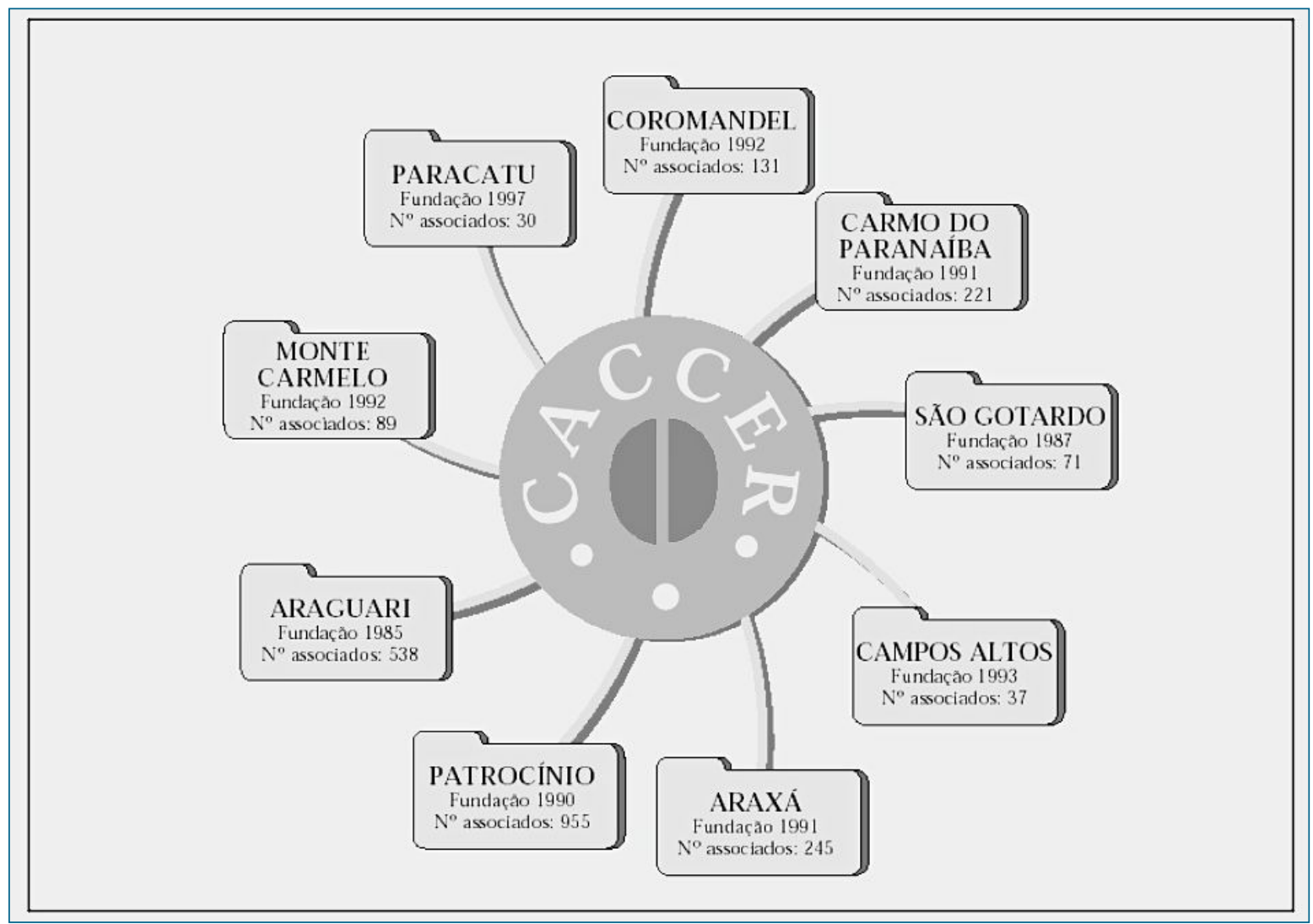

Fonte: SAES, 1997, p.21.

produtores passaram a utilizá-la indevidamente, fazendo mistura de cafés e vendendo-os como Café do Cerrado. Tal prática se tornou motivo de grande preocupação para os produtores, como atesta Aguinaldo (2006):

Você chega à Europa, você vê um monte de lista de vendedor de café, com Sul de Minas, Cerrado, só que não é do Cerrado, não do nosso. O Cerrado é muito grande, o Oeste da Bahia, por exemplo, é Cerrado, não deixa de ser, agora Café do Cerrado é dessa área delimitada.

Nos já vimos um monte de exemplos e você vai ver que não é nosso, o tipo de concha, defeitos, paladar... E falam que é Cerrado, e não é. Utilizando nosso nome sem controle nenhum. Eu sei de muitas empresas que estão aqui, a gente viu e conhece estes fatos, exportadores grandes que vêm da Zona da Mata, do Sul de Minas e que vende dizendo que é Cerrado. Os cafés do Sul de Minas e da Zona da Mata são bons cafés? São, mas não são nossos. Então, nós produzimos 3 milhões de sacas, mas dá a impressão que produzimos 7 milhões, isso está errado, então passamos a trabalhar em cima da defesa do produtor. (LIMA, em entrevista ao autor, 2006).
Essa defesa do produtor a que se refere Aguinaldo era o temor de que a marca Café do Cerrado fosse prejudicada pela variação de qualidade dos cafés vendidos com o uso indevido da marca. Dessa forma, o CACCER começou a pleitear a exclusividade na classificação e emissão de laudos para a utilização da marca. Tendo o controle sobre o processo, imaginava que a qualidade estava assegurada, resguardando o produtor e o comprador que continuaria pagando um preço mais elevado devido à qualidade assegurada do produto.

Mesmo antes de ser reconhecido oficialmente como único classificador do Café do Cerrado, o CACCER já havia implementado um novo programa de certificação para o uso da marca. Para os gestores do CACCER estava claro que não bastava apenas a delimitação da região produtora, era necessário também geri-la de modo que o Conselho tivesse o controle de toda a cadeia 
Figura 2. Região produtora do Cerrado Mineiro.

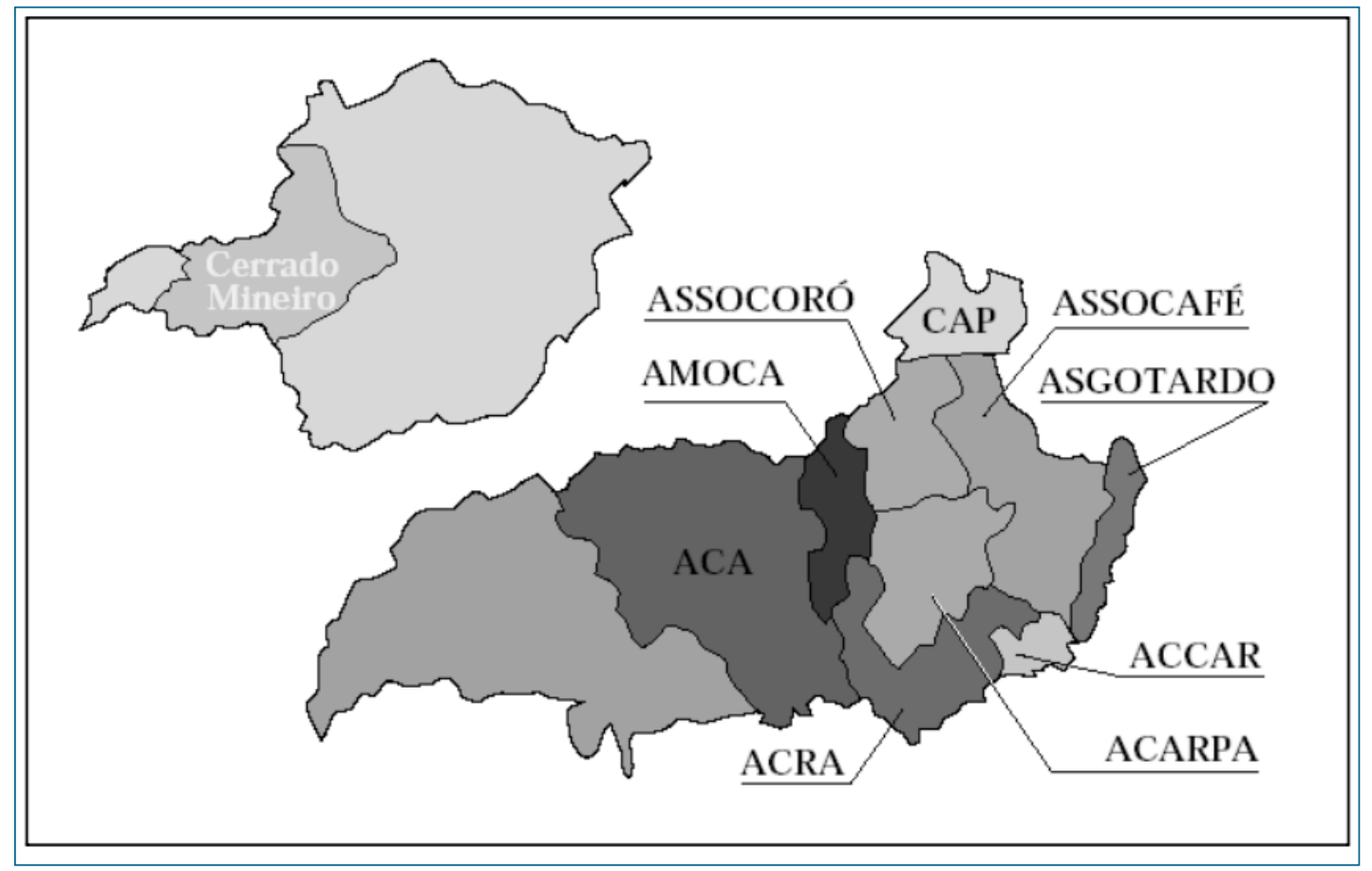

Fonte: SAES, 1997, p. 19.

produtiva do café do Cerrado, desde a fazenda até o consumidor final. Foi criada então uma Cadeia de Custódia dividida em dois grupos: o dos certificáveis e dos credenciáveis. Os certificáveis seriam a propriedade, o modelo de produção e o produto, no caso cada lote de café. O grupo dos credenciáveis é formado por armazéns, exportadores, importadores, torrefadores e os pontos de venda e de serviço.

$\mathrm{Na}$ concepção do CACCER, a Cadeia de Custódia é formada por um conjunto de entidades credenciáveis, que são participantes que têm como compromisso preservar a integridade de um determinado produto certificado sob sua custódia a partir de seu ponto de produção até o consumo final. No caso do Café do Cerrado, o lote de café é o artigo certificado sob custódia que deverá seguir íntegro até o consumidor final. Dessa forma, o CACCER passou a gerir por completo todo o processo produtivo do Café do Cerrado. Isso significa que qualquer produtor ou comprador que quiser usar a marca Café do Cerrado tem que se submeter a um processo de avaliação e à assinatura de termos de compromisso elaborados pelo CACCER. Nas palavras de Aguinaldo:
Então, é uma série de proteções que nós estamos colocando em prática agora nas fazendas, a partir de agora ninguém vai poder exportar ou vender no mercado interno, usando a palavra 'Cerrado'; Café do Cerrado, produzido no Cerrado, tipo Cerrado, não pode. A não ser que tenha a fazenda e o produto certificado pelo CACCER, só por dentro do CACCER e aí se submetendo a política de qualidade da Associação. (LIMA, em entrevista ao autor, 2006).

Destaca-se que esta nova política de certificação visa a algo mais que proteger a marca, o produtor e o produto da região. Ela é o passaporte para atender a uma nova demanda do mercado de alimentos, principalmente dos países centrais, ligada à segurança alimentar. Esta política está baseada no rastreamento do alimento desde sua origem. No caso do café, tal prática seria impossível com o sistema tradicional de comercialização, no qual as sacas que saem das fazendas são misturadas com outras, perdendo-se, assim, a possibilidade de rastrear a origem.

Com o novo sistema de certificação, cada saca leva um código de barras indicando sua origem, de maneira que o comprador possa identificar a região e a fazenda onde foi produzida. Em 
casos especiais, como de defeito em algum lote, é possível identificar até o mesmo o talhão onde foi colhido o lote defeituoso. É pertinente observar que este nicho de mercado ainda é pequeno, ligado a um público de poder aquisitivo elevado. De qualquer forma, para o produtor constitui um ótimo negócio, pois isso eleva o valor agregado do produto, garantindo um excelente preço final de venda ${ }^{14}$.

Criada a certificação, foi necessário convencer os produtores da região a certificarem suas fazendas, passando pelos critérios de avaliação do CACCER. Esse ponto é um divisor de águas entre os produtores de Patrocínio: submeter-se ao processo de classificação antes de qualquer coisa significa custo, pois os produtores têm que cumprir uma série de exigências sem as quais o produto não consegue abertura no mercado externo. Então, foi criado um programa de concessão de estrelas, variando de uma a quatro. Quanto maior o grau de exigências cumpridas, maior o número de estrelas. O primeiro ponto importante a ser cumprido é o código de conduta da propriedade de Café do Cerrado, que contempla os seguintes pontos:

a. Condução agronômica responsável, contemplando utilização de produtos agroquímicos ou de proteção de cultivos registrados para a cultura. Prevê utilização preferencialmente dos conceitos de Manejo Integrado de Pragas e Doenças. A condução obrigatoriamente tem supervisão de profissional qualificado, e estabelece-se conjunto solidário entre funcionários, produtos, ações e condições da lavoura.

b. Pleno atendimento da legislação trabalhista brasileira, contemplando aspectos de segurança laboral, medicina do trabalho e de promoção profissional dos funcionários.

|| ||||||||||||||||||||||||||||||||||||

14 Este nicho de mercado é atendido pelos denominados microlotes, que são cafés especiais com particularidades especiais de corpo e aroma, que conseguem preços mais elevados que o café denominado commodity, produzido em larga escala. Esse nicho de mercado vem se tornando uma alternativa para pequenos produtores de café, que se não conseguem competir em escala com os grandes produtores, ao aplicarem técnicas particulares de produção em combinação com fatores de ordem física. c. Pleno atendimento da legislação ambiental brasileira, abrangendo desde aspectos de gerenciamento de risco ambiental até preservação e estímulos ao incremento da biodiversidade na propriedade.

d. Completo registro de todas as atividades e ações na unidade produtiva, permitindo utilização de mecanismos de rastreabilidade no sentido amplo, seja no tocante á sanidade do produto final café, seja relativo ao acompanhamento dos custos de produção.

Uma vez conseguida a certificação, a propriedade passa a exibir em sua entrada uma placa padronizada.

Nos Estatutos do CACCER, consta o seguinte item: considerando-se que o CACCER é a entidade representativa dos produtores da Região Demarcada do Cerrado Mineiro, o modelo de certificação adotado prevê mecânica de inclusão de produtores de todo porte, desde familiares até os de grande porte, possibilitando, assim, a todos os cafeicultores da região acesso ao Programa de Certificação e, posteriormente, aos mercados que o exigem. Assim, a certificação está disponível para todos, desde que cumpridas as exigências. Contudo, emerge neste ponto uma questão importante: o fator custo de produção, com o qual muitos produtores ou não podem, ou não querem arcar. De todo modo, o exposto mostra que a certificação não é acatada por todos os produtores da região, que continuam a vender seu café por canais tradicionais. Ademais, o próprio sistema ACARPA-CACCER não é uma unanimidade: verificou-se que nem todos os produtores do município de Patrocínio estão filiados à associação.

Em uma explicação simplista - e até mesmo preconceituosa - os dirigentes do conselho argumentam que os $35 \%$ - número bastante expressivo - dos produtores não integrados são "cabeças duras" que não se abrem às novas experiências e tecnologias e ainda vaticinam que produtores que não aderirem às novas técnicas de produção e comercialização tendem a quebrar ou simplesmente permaneceram no nível da subsistência. 
Figura 3. Identificação Padrão de Propriedade Certificada.

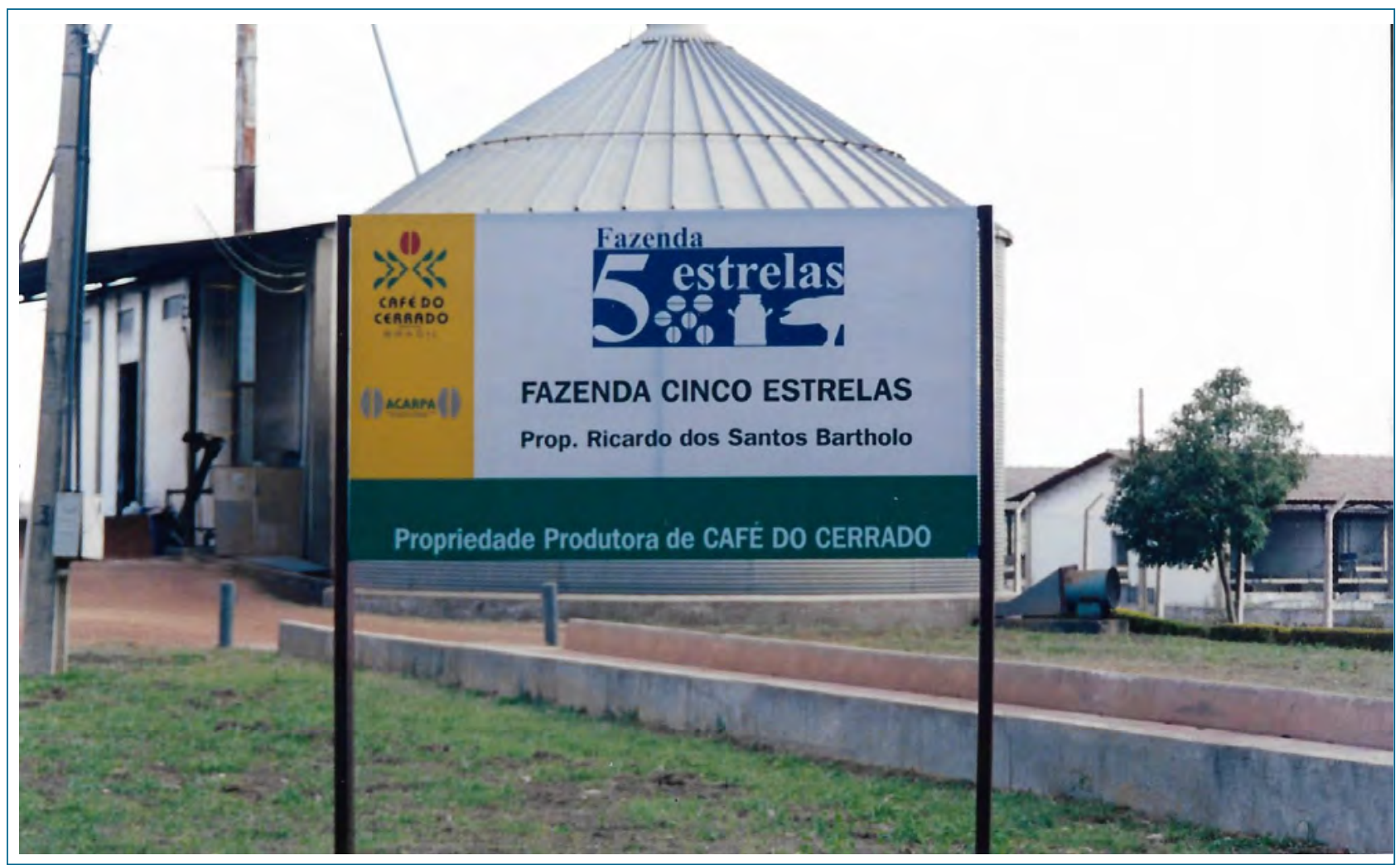

Fonte: Acervo do autor. 05/06/2015.

No caso específico dos produtores ligados ao Conselho, é cada vez maior o emprego de tecnologia avançada tanto no trato dos cafezais quanto no processo de comercialização. Os índices de produtividade por hectare e o nível de mecanização da lavoura é mais elevado do que em qualquer outra região do país. Isso se deve ao fato, em larga medida, do nível de capitalização dos produtores. Conforme mencionamos anteriormente, há um predomínio de médios e grandes produtores, o que somado ao relevo plano da região favorece a mecanização da produção, esta, por sua vez, impulsionada também devido à dificuldade de arrendar mão de obra.

Olhar para o café do Cerrado, ao menos em uma visão superficial, nos levaria a concordar com a tese de Buainaim (2015), quando argumenta:

(...) a principal fonte de formação e apropriação de riqueza no campo era a terra (especialmente antes da década de 1980), o que inevitavelmente atribuía forte centralidade à sua posse e propriedade. Por essa razão, o espaço rural e a agricultura foram determinados pelos mecanismos de ocupação das fronteiras em processos de acumulação principalmente patrimoniais, baseados na terra e no uso de mão de obra de baixíssima remuneração, sem que a produtividade jamais tivesse sido o motor principal do processo. Já o novo padrão introduz o capital "em todas as suas modalidades" no centro do desenvolvimento agrícola e agrário. Rebaixa o papel da terra, pois a produção e as rendas agropecuárias passam a depender, crescentemente, dos investimentos em infraestrutura, máquinas, tecnologia e na qualidade da própria terra, além de investimentos em recursos ambientais e no treinamento do capital humano.

(Buainaim, 2015, p. 110)

Um olhar mais acurado nos mostra que ainda estamos longe de desprezar a propriedade da terra, como mostra Mattei (2015), como elemento direto para a produção agropecuária no país. Uma grande parcela de propriedades e proprietários está excluída desse modelo "moderno" de produção, o que nos leva a questionar a sua sustentabilidade, se não como um todo, ao menos em determinadas regiões.

No que tange ao café do Cerrado, sua marca, sua associação e sua exportadora, constitui um case de sucesso no mercado internacional. Recentemente 
o CACCER obteve uma extraordinária vitória: a certificação e a marca "Café do Cerrado" foram lançadas e aceitas nos Estados Unidos, abrindo um canal de comercialização direto entre o Cerrado Mineiro e o maior mercado consumidor de café do mundo. Isso com identidade própria, passando ao largo da chancela "Café do Brasil".

\section{Conclusão}

Sem a pretensão de esgotar o assunto, podemos observar que o agronegócio do café no Brasil vem passando por importantes transformações estruturais, seja na busca pela qualidade do produto, revertendo a má fama construída historicamente, seja pela busca de uma forma produtiva sustentável no nível político, ambiental, econômico e social, garantindo uma melhor qualidade de vida para todos os atores e agentes envolvidos na cadeia produtiva.

O mercado consumidor de café nas últimas décadas vem se sofisticando e abrindo novas possibilidades de mercado para variados perfis de produtores de café, desde os grandes produtores, responsáveis pela produção de grande volume do produto, fundamentais para atender a demanda do expansivo consumo de café em cápsulas, até mesmo o pequeno produtor, que pode se inserir no crescente segmento dos cafés especiais, no qual fatores como boas práticas ambientais e sociais são credenciais, além da qualidade do produto, para atender uma nova demanda de consumidores.

A iniciativa mostrada neste estudo é apenas uma das múltiplas que estão sendo tomadas com o intuito de dinamizar o agronegócio do café em nosso país. Novas experiências com novos parâmetros técnicos produtivos e mercadológicos estão projetando nosso produto no mercado externo, bem como vêm criando novos segmentos no mercado interno, abrindo novos nichos de mercado.

\section{Referências}

BECKER, Dinizar F. A economia política do (des)evolvimento regional contemporâneo. In Becker, Dinizar F. Wittmann, Milton Luiz. Desenvolvimento Regional: Abordagens Interdisciplinares. Rio Grande do Sul: 2003, Edunisc.
BERNARDES, Júlia Adão. As Estratégias do Capital no Complexo da Soja. In: CASTRO, Iná Elias de. Brasil, Questões Atuais da Reorganização do Território. Rio de Janeiro: Bertrand Brasil, 1996.

BOURDIN, Alain. A Questão Local. Rio de Janeiro: DP\&A, 2004.

BROGGIO, Celine. A Dinâmica Territorial da Cafeicultura Brasileira - Dois Sistemas de Produção em Minas Gerais. In: Revista Território. Rio de Janeiro, n. 6, LAGET/UFRJ, 1999.

BUAINAIM, Antônio Márcio. Sete Teses Sobre o Mundo Rural Brasileiro. Revista de Política Agrícola. Ano XXII, n. 2, Abr./Maio/Jun. 2013.

CORRÊA, Roberto Lobato. Interações Geográficas. In Castro, Iná Elias de. (Org.). Explorações Geográficas. Rio de Janeiro: Bertrand Brasil, 1997.

CORRÊA, Roberto Lobato, Roberto Lobato. Trajetórias Geográficas. Rio de Janeiro: Bertrand Brasil, 1997.

CORRÊA, Roberto Lobato, Roberto Lobato. Regiões de Influência das Cidades. Rio de Janeiro: IBGE, 1987.

COSTA, Rogério da. Por um novo conceito de comunidade: redes sociais, comunidades pessoais, inteligência coletiva. Interface (Botucatu), mar./ago. 2005, v.9, n.17, p. 235-248

DALLABRIDA, Valdir R. Dinâmica Territorial do Desenvolvimento. In Becker, Dinizar F. Wittmann, Milton Luiz. Desenvolvimento Regional: Abordagens Interdisciplinares. Rio Grande do Sul: Edunisc, 2004.

DIAS, Leila Christina. Redes: Emergência e Organização. In: Castro, I. E.; Gomes, P. C. C. e Corrêa, R. L. (Org.). Geografia Conceitos e Temas. Rio de Janeiro: Bertrand do Brasil, 1995.

DIAS, Leila Christina. (Org). Redes, Sociedades e Territórios. Rio Grande do Sul: Edunisc, 2005.

ERTHAL, Rui. Os Complexos Agroindustriais no Brasil. Rio de Janeiro, 1997. Mimeo.

FARINA, Elizabeth. O Agribusiness do Café no Brasil.São Paulo: IPEA. PENSA, 1997.

GIORDANO, Samuel R. Competitividade Regional e Globalização. São Paulo. (Tese de Doutorado) Departamento de Geografia - Universidade de São Paulo, 1999.

GOMES, Paulo César da Costa. O conceito de região e sua discussão. In: CASTRO, I.; GOMES, P.C.C.; CORRÊA, R. L. (Orgs.) Geografia: conceitos e temas. Rio de Janeiro: Bertrand Brasil, 1995.

HARVEY, David “A transformação político-econômica do capitalismo no final do século XX" (parte II). In: A Condição Pós-Moderna. São Paulo: Loyola. 1992.

LEITE, Sérgio. Políticas Públicas e Agricultura no Brasil. Rio Grande do Sul: Editora da Universidade UFRGS, 2001.

LEITÃO. Miriam. Os Rumos do Agronegócio. Panorama Econômico. Caderno de Economia. Jornal O Globo. 05/05/2004. 
MATTEI, Lauro. Considerações acerca de teses recentes sobre o mundo rural brasileiro. Revista de Economia e Sociologia Rural, Brasília,DF. Sociedade Brasileira de Economia e Sociologia Rural - Sober. v. 52, suplemento 1. 2015.

MATTOSO, Jorge. A Desordem do Trabalho. São Paulo: Scritta, 1995.

MAZZALI, Leonel. O Processo Recente de Modernização Agroindustrial. São Paulo: Edunesp, 2000.

MONIÉ, Fréderic. A Mobilização Produtiva dos Territórios. Rio de Janeiro: DP\&A, 2003.

MULLER, Geraldo. Complexo Agroindustrial e Modernização Agrária. São Paulo: Hucitec, 1989.

NEVES, Marcos F. ILLY Café e os desafios do crescimento no Brasil. São Paulo: Seminários PENSA de Agronegócios, 2002.

OLIVEIRA, Ariovaldo Umbelino de. Agricultura Brasileira Transformações Recentes. In: ROSS, Jurandyr. Geografia do Brasil. São Paulo: Edusp, 1996.

RAFFESTIN, C. Por uma geografia do poder. São Paulo: Ed. Ática, SP. 1993.

SAES, Maria Sylvia. CACCER: Coordenando Ações Para a Valorização do Café do Cerrado. ão Paulo: Seminários Pensa de Agronegócios, 1997.

SANDRONI, Paulo. Novo Dicionário de Economia. São Paulo: Best Seller, 1994.

SANTOS, M. A natureza do espaço - Técnica e tempo, razão e emoção. São Paulo: Ed. Hucitec, 2002.

SANTOS, M. A Natureza do Espaço. São Paulo: Edusp, 2002.

SANTOS, M. O Brasil Território e Sociedade no Século XXI. Rio de Janeiro: Record, 2001.

SANTOS, M. Por uma outra globalização - Do pensamento único à consciência universal. Rio de Janeiro: Ed. Record, RJ. 2000.
SILVA, Augusto C. P. da. Discurso e Práticas Institucionais no Rio de Janeiro. In: RUA, João. Paisagem, Espaço e Sustentabilidades: uma Perspectiva Multidimensional da Geografia. Rio de Janeiro: Editora Puc, 2007.

SILVA, Augusto C. P. da, Augusto C. P. da. Em Busca do Rural Moderno no Estado do Rio de Janeiro: projetos, estratégias e gestão do território, exemplificados no norte e noroeste fluminense. Tese (doutorado) Rio de Janeiro: IGEO/ UFRJ, 2005.

SILVA, Augusto C. P. da, Augusto C. P. da. Cooperativismo e Autonomia: pela transformação das práticas e dos objetivos associativistas no espaço rural brasileiro. Revista Geo-Uerj. Revista do Departamento de Geografia. Universidade do Estado do Rio de Janeiro, n. 12, 2002, p. 33-46.

SILVA, Carlos A. F. Corporação e Rede em Áreas de Fronteira. Cuiabá: Entrelinhas, 2003.

SORJ, Bernardo. Estado e Classes Sociais na Agricultura Brasileira. Rio de Janeiro: Guanabara, 1986.

SPERS, Eduardo Eugênio. Segurança do Alimento. In: Zylbersztajn, Décio. In: Gestão da Qualidade no Agribusiness. São Paulo: Atlas, 2003.

TAVARES, Estela. A Questão do Café Commodity e sua Precificação: o "C Market" e a Classificação, Remuneração e Qualidade do Café. Campinas. (Tese de Doutorado). Departamento de Economia - UNICAMP, 2002.

WITTMANN, Milton Luiz. (Org). Desenvolvimento Regional, Capital Social, Redes e Planejamento. Santa Cruz do Sul: Edunisc, 2004.

ZYLBERSZTAJN, Décio. O Sistema Agroindustrial do Café. Porto Alegre: Ortiz, 1993.

\section{Marcelo Orozco Morais}

Licenciado em Geografia pela Universidade Federal Fluminense. Mestre em Geografia pela Universidade Federal Fluminense. Doutorando em Geografia pela PUC-Rio. Mestre em Geografia pela Universidade Federal Fluminense. Professor de Geografia do Centro Federal Tecnológico Celso Suckow da Fonseca - CEFET/RJ e Membro do Grupo de Pesquisa Gestão Territorial no Estado do Rio de Janeiro (GeTERJ), da PUC-Rio.

E-mail: orozco.morais@gmail.com 